\title{
Multifocal bleaching of Millepora dichotoma in the Gulf of Aqaba (Eilat), Red Sea
}

\author{
Assaf Zvuloni ${ }^{1,2,3, *}$, Rachel Armoza-Zvuloni ${ }^{2,3,4}$, Yonathan Shaked ${ }^{3}$ \\ ${ }^{1}$ Israel Nature and Parks Authority, PO Box 667, Eilat 88000, Israel \\ ${ }^{2}$ Department of Zoology, Faculty of Life Sciences, Tel Aviv University, Tel Aviv 69978, Israel \\ ${ }^{3}$ The H. Steinitz Marine Biology Laboratory, The Interuniversity Institute for Marine Sciences of Eilat, PO Box 469, \\ Eilat 88103, Israel \\ ${ }^{4}$ National Centre for Mariculture, Israel Oceanographic and Limnological Research, PO Box 1212, Eilat 88112, Israel
}

\begin{abstract}
The zooxanthellate hydrocoral Millepora dichotoma is an important framework builder of shallow reefs in the Gulf of Aqaba (Red Sea). In this study, we document and characterize the emergence of multifocal bleaching (MFB), a new syndrome in M. dichotoma. MFB is characterized by bleached spots scattered over the colony. The establishment of MFB in M. dichotoma at the study site was surprisingly rapid. We first noticed this phenomenon and assessed its prevalence in February 2010, and re-assessed it 1 yr later, in February 2011. The prevalence of MFB along the reef crest at a depth of $0.5 \mathrm{~m}$ is extremely high (63 and $67 \%$ in 2010 and 2011, respectively), significantly higher than along the fore-reef at a depth of $2.5 \mathrm{~m} \mathrm{(16}$ and $31 \%$ in 2010 and 2011, respectively). Spatial analyses were used to characterize the distribution of MFB across 2 spatial scales on the reef: among-transects scale $(<800 \mathrm{~m})$ and within-transect scale $(<60 \mathrm{~m})$. The results clearly show that the affected hydrocorals are aggregated over these 2 scales. While several factors may contribute to the observed pattern, the aggregated spatial distribution of the affected hydrocorals suggests that local and inter-colonial transmission play a significant role in the spread of MFB.
\end{abstract}

KEY WORDS: Multifocal bleaching $\cdot$ Millepora $\cdot$ Hydrocoral $\cdot$ Gulf of Aqaba $\cdot$ Eilat $\cdot$ Spatial pattern Resale or republication not permitted without written consent of the publisher

\section{INTRODUCTION}

Coral bleaching and infectious diseases have emerged worldwide as dominant drivers of reef coral population decline (Harvell et al. 2002). During the past few decades, bleaching and disease outbreaks have not only resulted in coral loss and severe decline in coral cover, but have also caused significant changes in coral community structure and reef-associated organisms (Hughes 1994, Aronson \& Precht 2001, Loya et al. 2001, Porter et al. 2001, Sutherland et al. 2004, van Woesik et al. 2011). Until recently, the intensively monitored coral reef of Eilat (northern tip of the Gulf of Aqaba, Red Sea) had been relatively free of bleaching and signs of coral diseases (Barash et al. 2005). However, in the past decade some of these diseases, including black-band disease (e.g. Zvuloni et al. 2009) and white-plaguelike disease (e.g. Barash et al. 2005), have appeared in the Gulf. The Eilat coral reef, where most of the present research was conducted, is an intensively studied reef. Scientists from the adjacent Interuniversity Institute for Marine Sciences continuously use this reef for, among other things, study of various aspects of coral and reef ecology (e.g. Loya \& Slobodkin 1971, Loya 1972, Riegl \& Piller 1999, Glassom et al. 2004, Abelson et al. 2005, Zvuloni et al. 2008a,b,c, 2009). A comprehensive reef monitoring program has been in place since 2003: the Israel National Monitoring Program at the northern Gulf of Aqaba (see INMP annual Scientific reports 2003-2010 at www.iui-eilat.ac.il/NMP). 
The zooxanthellate hydrocoral Millepora dichotoma is an important framework contributor to shallow reefs in the Gulf of Aqaba, forming a distinct 'Millepora zone' at a depth of 0.2 to $3 \mathrm{~m}$ (Loya \& Slobodkin 1971). In this study, we report an unusual bleaching pattern, consisting of numerous scattered bleached spots (see Fig. 1). This phenomenon was observed for the first time in February 2010 on M. dichotoma populations along the Gulf. We found affected hydrocorals at reefs as far apart as the Jordanian and Israeli coasts, at the northern tip of the Gulf, and the Straits of Tiran (Egypt) at its southern end, some $170 \mathrm{~km}$ away. Following the framework provided by Work \& Aeby (2006) to systematically describe and name diseases in corals (see 'Materials and methods') and the 'Underwater cards for assessing coral health on IndoPacific reefs' (Beeden et al. 2008), we termed this unusual bleaching, in which the bleached tissue and zooids within the spots are often visible (see Fig. 1d), 'multifocal bleaching' (MFB). In other locations around the world, similar focal bleaching has been reported, affecting the scleractinian corals Porites, Montipora and Acropora (Beeden et al. 2008). Work \& Abey (2006) reported ca. 1 to $3 \mathrm{~mm}$ multifocal tissue-loss in Millepora sp. In this study, we report for the first time on the emergence of MFB in Millepora. We provide (1) a qualitative description of the appearance of MFB on $M$. dichotoma, (2) a quantitative assessment of the prevalence of MFB in populations along the reefs at the Coral Nature Reserve in Eilat (Israel), and (3) a characterization of the spatial distribution of MFB.

\section{MATERIALS AND METHODS}

\section{Qualitative characterization of multifocal bleaching on Millepora dichotoma}

We employed the framework provided by Work \& Aeby (2006) to systematically describe the observed MFB and to use an appropriate terminology. Using this framework, we provide information on the distribution of the bleached spots on the colony, their edges, margins, shapes, color and size.

Both at the field and at the laboratory, we searched for potential organisms that may cause the observed MFB. Specifically, we were searching for a transparent organism, such as a flatworm or a ciliate, which theoretically may leave its 'footprints' on the hydrocoral. A total of 14 daytime dives between February 2010 and April 2011 and 2 night-time dives in April 2010 were performed in order to search for such an organism. We used a magnifying glass, and at night- time we also used a dive torch. In addition, 10 ca. $10 \times 10 \mathrm{~cm}$ fragments of the hydrocoral affected by MFB were collected from the reef and observed in the laboratory under a magnifying glass, a stereomicroscope (Nikon SMZ-1000) and a light microscope (Nikon E-200).

\section{Reef surveys}

Reef surveys were conducted at the Coral Nature Reserve in Eilat (from 29 30' 36.62" N, 34 ${ }^{\circ} 55^{\prime} 25.33^{\prime \prime} \mathrm{E}$ to $29^{\circ} 30^{\prime} 14.16^{\prime \prime} \mathrm{N}, 34^{\circ} 55^{\prime} 8.56^{\prime \prime} \mathrm{E}$ ), immediately following the discovery of MFB in the region in February 2010 and again 1 yr later in February 2011. In both surveys, twelve $60 \times 1 \mathrm{~m}$ belt-transects were randomly placed at 6 stations along the ca. $800 \mathrm{~m}$ long studied reef. At each station, 1 transect was placed on the reef crest at a depth of ca. $0.5 \mathrm{~m}$ and another on the forereef at a depth of ca. $2.5 \mathrm{~m}$. All colonies of $M$. dichotoma, the only species of hydrocoral observed within the belt transects, were counted. Colonies were classified as affected by MFB only if they revealed the typical signs of several bleached spots scattered over the colony (see Fig. 1). The beginning and end points of each transect were marked with an electric wire tied to the reef, enabling later transects placed on the reef to be situated over approximately the same areas. In February 2011, in addition to the sampling scheme described above, the location of hydrocorals along 2 of the 12 transects, 1 on the reef crest and 1 on the fore-reef, were recorded. This additional information was then used to assess the spatial pattern of affected hydrocorals within the transect-scale.

In order to describe the development of the bleached spots in affected colonies, 7 affected hydrocorals within the study site were tagged and photographed in March 2010. They were revisited and photographed again ca. 2 wk later, and thereafter in September 2010 and April 2011.

\section{Prevalence and spatial pattern of multifocal bleaching}

The prevalence of MFB (i.e. percentage of hydrocorals affected by MFB) was calculated for each transect. To satisfy statistical requirements, an arcsine transformation was performed and the data were tested for normality (Kolmogorov-Smirnov test) and homogeneity of variances (Levene's test). A 2-factor analysis of variance (ANOVA), followed by Tukey's post hoc test, was conducted in Statistica $8^{\circledR}$ to test the effects of depth and year on the prevalence of MFB. 
We employed spatial statistics to characterize the spatial distribution of hydrocorals affected by MFB across 2 spatial scales: (1) among-transects scale $(<800 \mathrm{~m})$, in which we examined whether affected hydrocorals tend to emerge more in certain transects than in others; and (2) within-transect scale $(<60 \mathrm{~m})$, in which we examined whether inter-colonial transmission of MFB forms aggregates of affected hydrocorals within the transect.

For the among-transects examination, $n_{i}$ is the number of hydrocorals and $m_{i}$ is the number of affected hydrocorals within transect $i$. Thus, the prevalence in percentages of MFB within this transect is given by:

$$
P_{i}=m_{i} \cdot 100 / n_{i}
$$

The variance of the prevalence values $\operatorname{Var}(P)$ for a set of 6 transects that was sampled at a specific depth (0.5 or $2.5 \mathrm{~m}$ ), during a specific year (2010 or 2011), was employed as a statistic. If the observed $\operatorname{Var}(P)$ is found to be significantly greater than would be expected had the affected hydrocorals emerged randomly (i.e. independent of their spatial location), we can conclude that affected hydrocorals tend to emerge more in certain transects than in others. That is, local transmission plays a role in the spread of MFB among transects. To test this hypothesis, we used a randomization test in which we generated 1000 realizations. In each realization the number of hydrocorals found within each transect $\left(n_{i}\right)$ and the total number of affected hydrocorals in a set of the 6 transects $\left(\sum_{i=1}^{6} m_{i}\right)$ were held fixed. Following these constraints, we shuffled all the affected and unaffected hydrocorals within the tested set of 6 transects and calculated $P_{i}$ for each transect according to Eq. (1). $\operatorname{Var}(P)$ was then calculated for each realization and the distribution of the 1000 values of $\operatorname{Var}(P)$ was considered to be a null distribution, against which the observed $\operatorname{Var}(P)$ value could be tested. We used 2-tailed tests with significance levels of 1 and $5 \%$, to determine whether the observed $\operatorname{Var}(P)$ was significantly different from the null expectation.

In the second case, in which we examined whether affected hydrocorals are spatially aggregated within transects, we used the nearest-neighbor method combined with a null hypothesis approach. If $\min \left(d_{j}\right)$ is the distance along the transect between affected hydrocoral $j$ and its affected nearest-neighbor hydrocoral, then the average of $\min \left(d_{j}\right)$ for a transect with $m$ affected hydrocorals is given by:

$$
\eta=\frac{\sum_{j=1}^{m} \min \left(d_{j}\right)}{m}
$$

If the observed $\eta$ is found to be significantly smaller than would be expected, had MFB appeared randomly along the transect, we can conclude that affected hydrocorals are aggregated within the transect, possibly because inter-colonial transmission plays a role in the spread of MFB within the tested transect. To test this hypothesis we generated 1000 realizations, where in each realization $m$ affected hydrocorals were randomly selected from the pool of all $n$ hydrocorals within the transect. $\eta$ was then calculated for each realization according to Eq. (2), and the distribution of the 1000 values of $\eta$ was considered to be a null distribution, against which the observed $\eta$ value could be tested.

\section{RESULTS}

\section{Qualitative characterization of multifocal bleaching on Millepora dichotoma}

Two species of millepores only, Millepora dichotoma and $M$. platyphylla, were observed to be affected by MFB (Fig. 1). Because M. platyphylla is relatively rare in the study site, colonies of this species were not found within the sampled areas. Affected hydrocorals display numerous bleached spots scattered over both shaded and non-shaded surfaces of the colony (Fig. 1a-c). Following Work \& Aeby (2006), the distribution of the bleached spots over the surface of the colony is described as 'multifocal'. In some cases, the number of the bleached spots is so high that neighboring bleached spots are coalesced and form a large bleached area (Fig. 1b). The bleached spots are commonly similar in shape and size, both within and among colonies, consisting of transparent tissue with distinct circular-edges and smooth margins, ca. $1 \mathrm{~cm}$ in diameter (Fig. 1c). The bleached tissue and zooids are often visible to the naked eye (Fig. 1d). The zooxanthellate algae within the bleached spots were not quantified; however, the discoloration of the tissue there suggests that it exhibits a very low density of algae or chlorophyll compared with the non-bleached tissue (Fig. 1e). The hydrocoral skeleton is not eroded and colonies that were tracked for more than 1 yr did not exhibit mortality due to MFB. Thus, the bleached spots are not colonized by algae or any other organisms. In addition, within this time frame affected colonies did not show signs of recovery. Using a magnifying glass, a binocular and light microscopy, we did not observe any organisms (e.g. ciliates, flatworms) which might have caused the observed MFB. Accumulation and development 



Fig. 1. Multifocal bleaching (MFB) in millepores. (a-e) Millepora dichotoma. (a) Colonies with a high number of bleached spots are common at the studied site (see also supplementary video at www.int-res.com/articles/suppl/m441p025_supp/). (b) Where bleached spots are very dense, neighboring spots may coalesce to form a large bleached area. (c) The bleached spots are very similar in size (ca. $1 \mathrm{~cm}$ in diameter) and shape, exhibiting distinct circular-edges and smooth margins. (d) A close-up of a bleached spot; the coral zooids extend from the transparent intact tissue within the spot. (e) Discoloration of tissue within the bleached spots. (f) M. platyphylla. A colony with dense bleached spots

of bleached spots over the surface of the hydrocorals occurs gradually (Fig. 2) until reaching a high density. Within many of the bleached spots there is a small area of non-bleached tissue near the edge (Fig. 1c). The overall impression is of a 'footprint', perhaps of an organism that attached itself to the coral. However, apart from feather-stars, which were not observed in abundance on hydrocorals and, based on their grasp, were unlikely to have caused the observed marks, no candidate organisms were identi- 

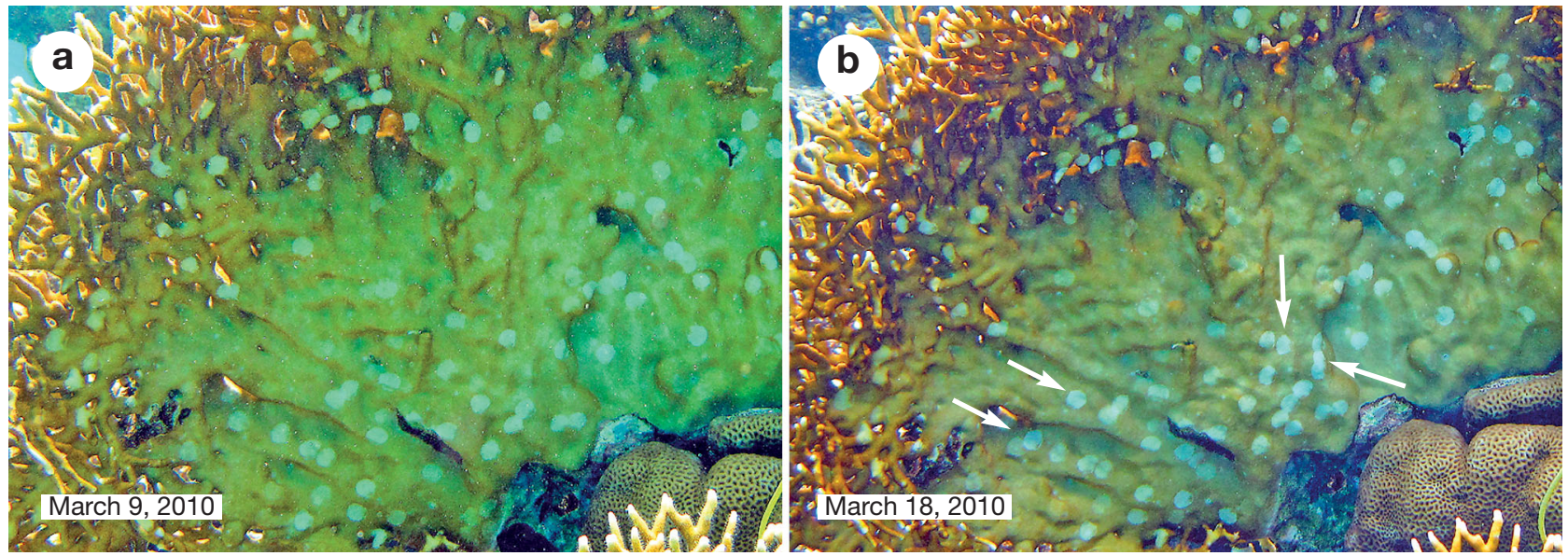

Fig. 2. Millepora dichotoma. Accumulation of bleached spots on the surface of a hydrocoral from (a) March 9 to (b) March 18, 2010. Several new spots were found (4 of these are marked with white arrows)

fied at the studied site, during daytime or night-time. Nor were any such organisms identified in the laboratory on fragments of the hydrocorals.

\section{Impact and spatial pattern of multifocal bleaching in the study site}

Within the twelve $60 \mathrm{~m}^{2}$ transects $\left(720 \mathrm{~m}^{2}\right.$ in total), 282 out of 576 hydrocorals ( $49 \%$ ) in 2010 and 316 out of 547 hydrocorals $(57.8 \%)$ in 2011 were found to be affected by MFB. A 2-factor ANOVA test reveals the prevalence of MFB to be significantly higher at $0.5 \mathrm{~m}$ than at $2.5 \mathrm{~m}$ depth (Fig $3 ; \mathrm{p}<0.001$ for both years). Significant differences in prevalence between 2010 and 2011 were not found at either depth.

We tested the spatial distribution of MFB across 2 spatial scales: among-transects and within-transect. In both cases, the hypothesis was rejected that hydrocorals affected by MFB emerge randomly, that is, independently of the spatial location of other affected hydrocorals (Fig. 4). At the among-transects scale, the observed $\operatorname{Var}(P)$ was greater than the null expectation at a significance level of $<1 \%$ in all cases except in 2010 at a depth of $2.5 \mathrm{~m}$, where the significance level was between 1 and $5 \%$ (Fig 4a). At the within-transect scale, the observed $\eta$ was smaller than the expected $\eta$ at both depths. At $2.5 \mathrm{~m}$ the significance level was $<1 \%$, and at $0.5 \mathrm{~m}$ it was between 1 and $5 \%$.

\section{DISCUSSION}

The present study reports for the first time the emergence of multifocal bleaching, an unusual bleaching pattern, on the hydrocoral Millepora dichotoma in the Gulf of Aqaba, Red Sea. The prevalence of MFB is extremely high, especially at a depth of $0.5 \mathrm{~m}$, where it reached ca. 63 and $67 \%$ in 2010 and 2011, respectively (Fig 3, supplementary video at www. int-res.com/articles/suppl/m441p025_supp/). This is much higher than the prevalence of any other coral disease recorded in the region. For example, the prevalence of black-band disease is $<0.9 \%$ (Zvuloni et al. 2009) and that of white-plague-like disease is ca. $10 \%$ (Barash et al. 2005). The establishment of MFB at the study site was surprisingly rapid. Although the study site is visited frequently, at least once a month, by A.Z. and almost daily by numerous other researchers, including the co-authors, MFB had



Fig. 3. Millepora dichotoma. Percentage of colonies from the surveyed population that were affected by multifocal bleaching (MFB) at 2 depths along the reef in the Coral Nature Reserve of Eilat during the initial survey in February 2010 and the follow-up survey in February 2011. Temporal differences are non-significant while the difference between reef crest $(0.5 \mathrm{~m})$ and fore-reef $(2.5 \mathrm{~m})$ is significant $(\mathrm{p}<$ 0.001 ). Error bars are mean $\pm S D, n=6$ transects 

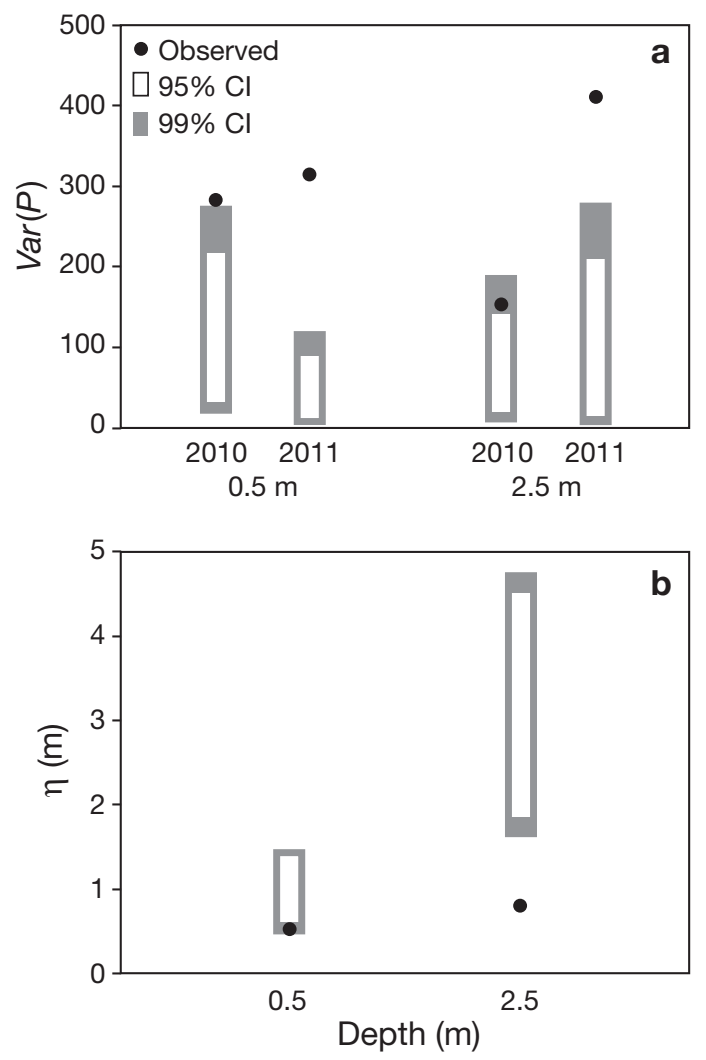

Fig. 4. Millepora dichotoma. Spatial pattern of colonies affected by multifocal bleaching (MFB). The white and grey bars represent, respectively, the 95 and $99 \%$ confidence interval (CI) envelopes generated by 1000 random realizations. (a) Among-transects scale: $(\bullet)$ observed variance of the prevalence values $[\operatorname{Var}(P)]$ in 4 sets of 6 transects, at 0.5 and $2.5 \mathrm{~m}$ depth, sampled in February 2010 and February 2011. Affected hydrocorals are significantly aggregated where the observed $\operatorname{Var}(P)$ values lie above the CI envelope. (b) Within-transect scale: $(\bullet)$ observed average distance between affected hydrocorals and their nearest-neighbor affected hydrocoral $(\eta)$ along 2 transects sampled at depths of 0.5 and $2.5 \mathrm{~m}$ in February 2011. Affected hydrocorals are significantly aggregated where the observed $\eta$ values fall below the CI envelope

never been noticed prior to February 2010, at which time the prevalence was already as high as ca. $63 \%$.

Despite the high prevalence of MFB found at the study site, the affected hydrocorals that have been tracked now for more than $1 \mathrm{yr}$ do not, as yet, exhibit mortality due to MFB. They show a high and stable number of bleached spots scattered over the surface of the colonies that are not colonized by algae or other organisms. However, as the zooxanthellae are known to provide a significant portion of the daily energetic requirements of the host via translocation of their photosynthates (Muscatine et al. 1984, Davies 1991), it is reasonable to assume that the loss of zooxanthellae in hydrocorals affected by MFB restricts their nutritional acquisition. Indeed, previous studies have suggested that bleaching in corals often results in reduced tissue lipid and protein content (e.g. Fitt et al. 1993, Jones \& Berkelmans 2011), reduced calcification and growth (e.g. Suzuki et al. 2003, Jones \& Berkelmans 2010), increased susceptibility to disease (e.g. Harvell et al. 1999), decreased reproductive capacity (reviewed by Coles \& Brown 2003, Jones \& Berkelmans 2011), and increased mortality (e.g. Glynn 1996, Loya et al. 2001). Other studies, in contrast, have found that certain coral species are less susceptible to bleaching and are able to survive and even recover from this phenomenon (Brown \& Suharsono 1990, Jokiel \& Coles 1990, Marshall \& Baird 2000, Jokiel \& Brown 2004, Armoza-Zvuloni et al. 2011). Grottoli et al. (2006), for example, showed that the Hawaiian coral Montipora capitata overcomes bleaching by changing its feeding strategy.

The mechanisms of the observed MFB, its etiology and mode of transmission are unknown. However, the results of the spatial analyses clearly demonstrate that affected hydrocorals tend to aggregate over the 2 spatial scales that were tested (i.e. among-transects and within-transect). A reasonable explanation for the observed aggregations of affected hydrocorals is that MFB is a syndrome caused by an infectious disease, in which local and inter-colonial transmissions play a significant role in its spread. Transmission mechanisms that form spatial aggregations of infected individuals may involve waterborne transmission by suspended pathogens or infectious material originating from affected individuals (as in blackband disease; see Zvuloni et al. 2009) and/or vectormediated transmission of a pathogen or infectious material (e.g. the fire worm Hermodice carunculata, a vector for the coral-bleaching pathogen Vibrio shiloi; see Sussman et al. 2003). In addition, direct contact can also contribute to the aggregation of symptomatic individuals, as unaffected individuals become infected by the direct transfer of pathogens from individuals that they are in physical contact with (e.g. aspergillosis; see Jolles et al. 2002).

Pattern analysis alone does not usually suffice to determine the pattern-generating processes, and in the absence of microbiological data we cannot explicitly state that MFB is a syndrome caused by an infectious disease. Although less likely, factors other than infection mechanisms could also contribute to the observed spatial patterns. For example, the aggregation of affected hydrocorals might be the outcome of spatial variation in marine microhabitat quality (e.g. variation in the hydrographic features of the microhabitat). Thus, if the observed MFB is 
caused by an abiotic stressor, hydrocorals that grow under poor conditions might be more affected by this stressor than those growing under better conditions. As an example, the observed MFB could be the outcome of UV-induced DNA damage (e.g. non-random somatic mutation), that tends to occur more frequently at certain locations on the reef with relatively high UV radiation. However, the surveyed transects were relatively uniform with respect to reef-structure, depth (and therefore UV radiation), bathymetry and flow direction.

Another possibility is that spatial genetic differences in resistance to MFB could lead to aggregation of affected individuals. While hydrocorals are not known to form clonal propagules or recruit philopatrically, we cannot exclude the possibility that fragments broken from the same hydrocoral attach to the reef close to one another and form genetically identical aggregates with similar resistance to MFB.

\section{SUMMARY}

In this study, we have documented and characterized for the first time the emergence of MFB, a new syndrome in Millepora. We observed MFB along the Gulf of Aqaba at locations some $170 \mathrm{~km}$ apart (at its northern and southern ends) and focused our analyses on the coral reef at the Coral Nature Reserve in Eilat. The MFB syndrome reported here was observed to affect only hydrocorals. However, it is important to note that hydrocorals are important contributors to the reefs along the entire Gulf of Aqaba (Loya \& Slobodkin 1971). Thus, damage to the 'Millepora zone' may impact many associated species of fishes and invertebrates that inhabit this zone. The spatial characterization of affected hydrocorals suggests that local and inter-colonial transmission play a role in the spread of MFB. However, the mechanisms of MFB in M. dichotoma, its etiology and mode of transmission await further investigations, where microbiological research will be essential to determine whether a pathogen is involved in the appearance of bleached spots on the hydrocorals. Continued monitoring may assist in unraveling some of the remaining questions, such as the possible seasonal pattern of multifocal bleaching, and its long-term impact on affected colonies and on the reef as a whole.

Acknowledgements. This work was supported by the Israel Science Foundation (ISF) and the Raynor Chair for Environmental Conservation Research (to Yossi Loya). We thank
Y. Loya, R. van Woesik, A. Kushmaro and E. KramarskyWinter for helpful suggestions and reviewing the manuscript, and N. Paz for her editorial assistance.

\section{LITERATURE CITED}

Abelson A, Olinsky R, Gaines S (2005) Coral recruitment to the reefs of Eilat, Red Sea: temporal and spatial variation, and possible e ects of anthropogenic disturbances. Mar Pollut Bull 50:576-582

Armoza-Zvuloni R, Segal R, Kramarsky-Winter E, Loya Y (2011) Repeated bleaching events may result in high tolerance and notable gametogenesis in stony corals: Oculina patagonica as a model. Mar Ecol Prog Ser 426: 149-159

Aronson RB, Precht WF (2001) White-band disease and the changing face of Caribbean coral reefs. Hydrobiologia 460:25-38

> Barash Y, Sulam R, Loya Y, Rosenberg E (2005) Bacterial strain BA-3 and a filterable factor cause a white plaguelike disease in corals from the Eilat coral reef. Aquat Microb Ecol 40:183-189

Beeden R, Willis BL, Raymundo LJ, Page CA, Weil E (2008). Underwater cards for assessing coral health on Indopacific reefs. www.Gefcoral.org.

$>$ Brown BE, Suharsono (1990) Damage and recovery of coral reefs affected by El Niño related seawater warming in the Thousand Islands, Indonesia. Coral Reefs $8: 163-170$

Coles SL, Brown BE (2003) Coral bleaching-capacity for acclimatization and adaptation. Adv Mar Biol 46: 183-223

Davies PS (1991) Effect of daylight variations on the energy budgets of shallow-water corals. Mar Biol 108:137-144

Fitt WK, Spero HJ, Halas J, White MW, Porter JW (1993) Recovery of the coral Montastrea annularis in the Florida Keys after the 1987 Caribbean 'bleaching event'. Coral Reefs 12:57-64

> Glassom D, Zakai D, Chadwick-Furman NE (2004) Coral recruitment: a spatio-temporal analysis along the coastline of Eilat, northern Red Sea. Mar Biol 144:641-651

> Glynn PW (1996) Coral reef bleaching: facts, hypotheses, and implications. Glob Change Biol 2:495-509

> Grottoli AG, Rodrigues LJ, Palardy JE (2006) Heterotrophic plasticity and resilience in bleached corals. Nature 440: 1186-1189

- Harvell CD, Kim K, Burkholder JM, Colwell RR, and others (1999) Emerging marine diseases-climate links and anthropogenic factors. Science 285:1505-1510

Harvell CD, Mitchell CE, Ward JR, Altizer S and others (2002) Climate warming and disease risks for terrestrial and marine biota. Science 296:2158-2162

Hughes TP (1994) Catastrophes, phase shifts and largescale degradation of a Caribbean coral reef. Science 265: 1547-1551

Jokiel PL, Brown EK (2004) Global warming, regional trends and inshore environmental conditions influence coral bleaching in Hawaii. Glob Change Biol 10:1627-1641

> Jokiel PL, Coles SL (1990) Response of Hawaiian and other Indo-Pacific reef corals to elevated temperature. Coral Reefs 8:155-162

> Jolles A, Sullivan P, Alker AP, Harvell CD (2002) Disease transmission of aspergillosis in sea fans: inferring process from spatial pattern. Ecology 83:2373-2378 
Jones A, Berkelmans R (2010) Potential costs of acclimatization to a warmer climate: growth of a reef coral with heat tolerant vs. sensitive symbiont types. PLoS ONE 5:e10437

> Jones A, Berkelmans R (2011) Tradeoffs to thermal acclimation: energetics and reproduction of a reef coral with heat tolerant symbiodinium type-D. J Mar Biol Vol. 2011, 185890

Loya Y (1972) Community structure and species diversity of hermatypic corals at Eilat, Red Sea. Mar Biol 13:100-123

Loya Y, Slobodkin LB (1971) The coral reefs of Eilat (Gulf of Eilat, Red Sea). Proc Zool Soc Lond 28:117-140

Loya Y, Sakai K, Yamazato K, Nakano Y, Sambali H, van Woesik R (2001) Coral bleaching: the winners and the losers. Ecol Lett 4:122-131

Marshall PA, Baird AH (2000) Bleaching of corals on the Great Barrier Reef: differential susceptibilities among taxa. Coral Reefs 19:155-163

Muscatine L, Falkowski P, Porter J, Dubinsky Z (1984) Fate of photosynthetic fixed carbon in light- and shadeadapted colonies of the symbiotic coral Stylophora pistillata. Proc R Soc Lond B Biol Sci 222:181-202

Porter J, Dustan P, Jaap W, Patterson K and others (2001) Patterns of spread of coral disease in the Florida Keys. Hydrobiologia 460:1-14

Riegl B, Piller WE (1999) Coral frameworks revisited-reefs and coral carpets in the northern Red Sea. Coral Reefs 18:241-253

Sussman M, Loya Y, Fine M, Rosenberg E (2003) The marine fireworm Hermodice carunculata is a winter reservoir and

Editorial responsibility: Charles Birkeland,

Honolulu, Hawaii, USA spring-summer vector for the coral-bleaching pathogen Vibrio shiloi. Environ Microbiol 5:250-255

Sutherland KP, Porter JW, Torres C (2004) Disease and immunity in Caribbean and Indo-Pacific zooxanthellate corals. Mar Ecol Prog Ser 266:273-302

Suzuki A, Gagan MK, Fabricius KE, Isdale PJ, Yukino I, Kawahata H (2003) Skeletal isotope microprofiles of growth perturbations in Porites corals during the 19971998 mass bleaching event. Coral Reefs 22:357-369

> van Woesik R, Sakai K, Ganase A, Loya Y (2011) Revisiting the winners and the losers a decade after coral bleaching. Mar Ecol Prog Ser 434:67-76

Work TM, Aeby GS (2006) Systematically describing gross lesions in corals. Dis Aquat Org 70:155-160

> Zvuloni A, Armoza-Zvuloni R, Loya Y (2008a) Structural deformation of branching corals associated with the vermetid gastropod Dendropoma maxima. Mar Ecol Prog Ser 363:103-108

Zvuloni A, Artzy-Randrup Y, Stone L, van Woesik R, Loya Y (2008b) Ecological size-frequency distributions: how to prevent and correct biases in spatial sampling. Limnol Oceanogr Methods 6:144-153

Zvuloni A, Mokady O, Al-Zibdah M, Bernardi G, Gaines SD, Abelson A (2008c) Local scale genetic structure in coral populations: a signature of selection. Mar Pollut Bull 56: 430-438

Zvuloni A, Artzy-Randrup Y, Stone L, Kramarsky-Winter E, Barkan R, Loya Y (2009) Spatio-temporal transmission patterns of black-band disease (BBD) in a coral community. PLoS ONE 4:e4993

Submitted: May 20, 2011; Accepted: August 29, 2011

Proofs received from author(s): October 28, 2011 